\title{
Prevention of vault prolapse in cases of procedentia using combined vaginal and laparoscopic approach for vault suspension: Agrawal's technique
}

\author{
Priti Agrawal*, Rishi Agrawal, Jyotirmay Chandrakar
}

\begin{abstract}
Department of Obstetrics, Gynecology and Infertility, Aarogya Hospital and Test Tube Baby Center, Raipur, Chhattisgarh, India
\end{abstract}

Received: 04 November 2020

Revised: 09 December 2020

Accepted: 10 December 2020

\author{
*Correspondence: \\ Dr. Priti Agrawal, \\ E-mail: drpritiagrawal15@gmail.com
}

Copyright: ( $)$ the author(s), publisher and licensee Medip Academy. This is an open-access article distributed under the terms of the Creative Commons Attribution Non-Commercial License, which permits unrestricted non-commercial use, distribution, and reproduction in any medium, provided the original work is properly cited.

\begin{abstract}
Background: The objective of the current study was to assess the need of vault suspension after completion of hysterectomy in all cases of procedentia to prevent vault prolapse and to reduce the operating time for sacrocolpopexy using combined vaginal and laparoscopic approach by two surgeons.

Methods: A total of 25 women undergoing surgery for procedentia were included. After completion of hysterectomy the need for vault suspension was assessed intraoperatively. In all cases polypropelene mesh was fixed vaginally to the uterosacral and cardinal ligaments. Vaginal vault was closed vaginally. Laparoscopic surgeon did laparoscopic sacrocolpopexy (LSC). Intraoperative and post-operative complications were then evaluated.

Results: Our average operating time was 35 minutes for vaginal hysterectomy and 15 minutes for LSC. The shorter duration of surgery was because mesh was fixed vaginally and trackers were used to fix the mesh to sacral promontory. Intraoperative complications like bladder, ureteric, bowel injuries and hemorrhage were nil in our series. Postoperative stay in hospital was uneventful and all cases were discharged on second postoperative day. Conversion rate to laparotomy was nil. All cases have completed follow up for 5 years with $100 \%$ subjective and objective improvement.

Conclusions: Restoration of vagina to its normal anatomic position remains the most important fact to prevent vault prolapse. Our technique is very easy, less time taking with negligible complication rates.
\end{abstract}

Keywords: Procedentia, Vault prolapse, Sacrocolpopexy

\section{INTRODUCTION}

The incidence of post hysterectomy vault prolapse varies from 0.2 to $0.43 \% .{ }^{1}$ After vaginal hysterectomy however women may be at increased risk of future vault prolapse depending on the indication of hysterectomy, age, parity, degree of prolapse, nutritional status, life style and associated problems like chronic cough, constipation, strenuous activity. The type of post hysterectomy prolapse that occurs will depend on which level vaginal support has failed. De lancey reported that failure to reattach the cardinal-utero sacral ligament complex adequately to the pubocervical fascia and recto vaginal fascia at the vaginal cuff during hysterectomy, to be the most common cause of vaginal vault prolapse. ${ }^{2}$ It is very important that the surgeon evaluates for vault prolapse in any patient presenting with prolapse uterus, because in many cases what appears to be a cystocele or rectocele is actually vault prolapse. ${ }^{3}$ This misdiagnosis leads to incomplete repair and usually causes shortening of the vagina because the apex is not suspended up to its natural position. In many cases even when the surgeon feels that 
after completion of hysterectomy and adequate pelvic floor repair the vault is approaching the introitus still vault suspension is not done considering it to be difficult procedure adding considerable time to the surgery. Numerous authors have published their experience of laproscopic sacrocolpopexy (LSC) for management of post hysterectomy vault prolapse. Ours is the first study where we have introduced mesh vaginally and undertaken LSC in all cases of procedentia undergoing vaginal hysterectomy, in order to prevent future vault prolapse.

The present study was conducted at Aarogya hospital and test tube baby centre, Raipur with the objectives, to assess the need of vault suspension after completion of hysterectomy in all cases of procedentia to prevent vault prolapse, to reduce the operating time for sacrocolpopexy using combined vaginal and laparoscopic approach by two surgeons and to assess the morbidity and success rates of the procedure with adequate post-operative follow up of the patients.

\section{METHODS}

The current study was a prospective study conducted at department of Obstetrics \& Gynecology, Aarogya Hospital and Test Tube Baby Centre, Raipur from $1^{\text {st }}$ January 2008 to $1^{\text {st }}$ January 2020. All cases were operated in between $1^{\text {St }}$ January 2008 to $1^{\text {st }}$ January 2015 and follow up completed on $1^{\text {st }}$ January 2020.

The study protocol was approved by Institutional Review Board. Informed written consent was obtained from all patients before opting for the surgical procedure.

\section{Inclusion criteria}

All cases of procedentia, (refers to complete prolapse beyond the level of the hymen distally such that the uterus is permanently protruding out of the vagina) 3 who had completed childbearing and were willing for hysterectomy were included.

\section{Exclusion criteria}

Patients with acute infection such as cystitis, bacterial or fungal vaginitis, pelvic inflammatory disease, acute venous thromboembolism, uncontrolled hyperglycemia, bleeding diasthesia or the need for anticoagulation, fistulas such as vesicovaginal, rectovaginal fistulas, previous pelvic prolapse repairs, associated pathology like endometriosis, ovarian, endometrial or cervical malignancy were excluded from the study.

A total of 25 women undergoing surgery for procedentia were included. A complete preoperative evaluation of all patients was done with a thorough history, physical examination and laboratory test as per RCOG Guidelines and by Nygard et al Table (1 and 2). ${ }^{4-6}$ Counselling of all patients was done regarding the technique, complications during the surgery and after the procedure. All the patients between the age group of 25-40 years were also given the choice of uterus preserving surgery i.e. laparoscopic sacrohysteropexy but all our patients had completed childbearing hence they opted for hysterectomy. In all patients below 45 years of age ovaries were preserved. Follow-up was explained and written consent was taken. Prior to surgical intervention coexisting conditions like severe anemia, chronic cough, hypertension, diabetes mellitus were controlled. Urinary tract infections were treated. Vaginal preparation was done using vaginal packing with betadine guage in all cases for 3 days preoperatively. Soft diet and laxatives were given for 3 days prior to surgery. All pre-operative preparations were done on outpatient basis.

\section{Surgical technique}

All patients were given spinal anesthesia. At the time of performing laparoscopy patients were either given short acting muscle relexant and intermittent positive pressure ventilation (IPPR) was done, if required then endotracheal intubation was done. All patients were placed in modified lithotomy position and two surgeons worked simultaneously one from vaginal route and other from abdominal route. After performing vaginal hysterectomy (Figure 1A) the vault edges were temporarily approximated using 2-3 Allis forceps (Figure 1B) and vaginal surgeon redeposited the vaginal apex up to the level just below pubic symphysis and reassessed for cystocele and rectocele (Figure 1C). In cases requiring cystocele repair then anterior colporraphy was done. A rectangular polypropylene mesh $6 \times 4 \mathrm{~cm}$ was taken, ends were then overlapped to convert it into a cylinder and 2-3 sutures were applied equidistant using prolene 2-0 suture (Figure 1D).

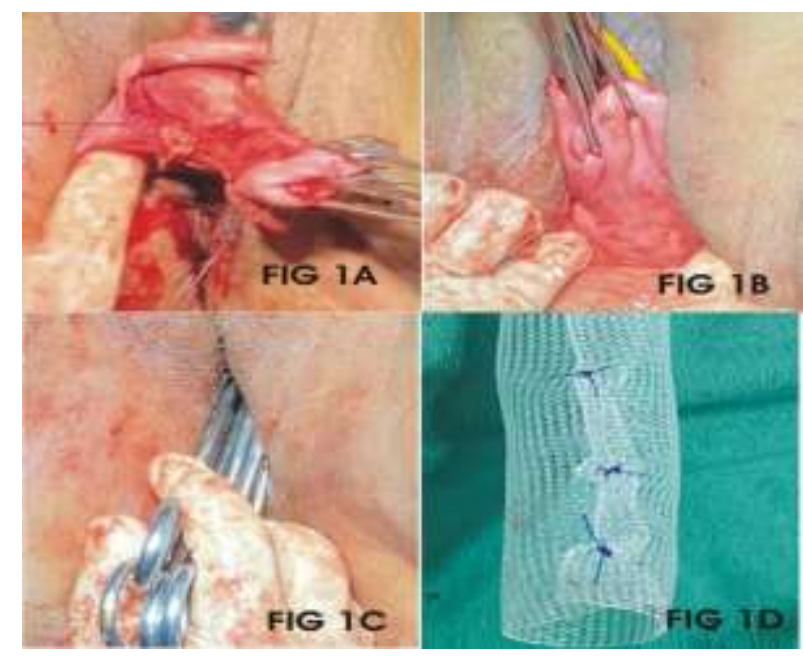

Figure 1: A) Vaginal hysterectomy being done, B) Vault edges being approximated temporarily using Allis forceps, C) Vaginal apex being redeposited and reassessed for cystocele and rectocele,

D) Polypropylene mesh being converted into cylinder. 
This cylindrical mesh was then introduced inside the vaginal cuff after removing the Allis forceps. The mesh was then sutured to cardinal and uterosacral ligaments, pubo vesicocervical fasicia anteriorly and rectovaginal fascia posteriorly with prolene 2-0 using 3-4 separate stitches (Figure 2A). The mesh placement was such that it was approximately one centimeter away from the vaginal margins. Vaginal vault was then closed by vaginal surgeon using vicryl number -1 on round body needle. (Figure 2B) Vaginal packing done with betadine gauge. Then laparoscopic surgeon created $\mathrm{CO}_{2}$ pneumoperitoneum using verses needle introduced through umbilicus at intra-abdominal pressure of $10 \mathrm{~mm}$ of $\mathrm{Hg} .30^{\circ}, 5 \mathrm{~mm}$ telescope (stryker 1488 system) was then introduced through umbilical port. Two accessory ports were made in a curved fashion on either side in midclavicular line $4 \mathrm{~cm}$ lateral and $2 \mathrm{~cm}$ below the umbilical port. Pneumoperitoneum was maintained at intra-abdominal pressure of $10 \mathrm{~mm}$ of $\mathrm{Hg}$. In few cases additional $4^{\text {th }}$ port if required was made to retract the bowels. Dissection over sacral promontory completed with laparoscopic monopolar scissors and bipolar cautery. Figure $2 \mathrm{C}$ traction over mesh given and tension free mesh fixation done over anterior longitudinal ligament of sacral promontory using 3-5 tackers (protack autofixation device $5 \mathrm{~mm}$ ) (Figure 2D).

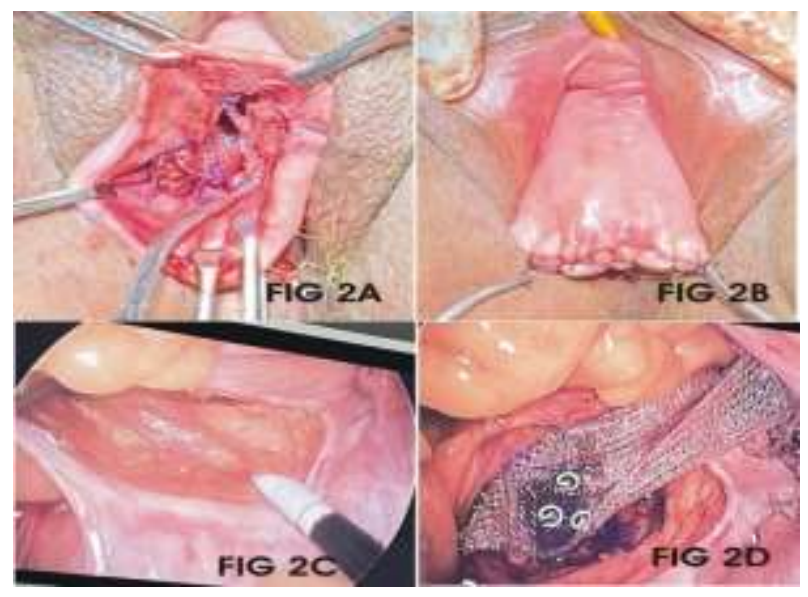

Figure 2: A) Mesh being fixed to vault vaginally, B) Vaginal vault closed, C) Dissection over sacral promontory, D) Mesh fixation over sacral promontory using tackers.

Excess mesh trimmed and removed from port site. Reperitonisation done. Heaemostasis checked and all quadrants of abdomen visualized for any unrecognized port site or cautery injury or existing intra-abdominal pathology. Desufflation done and ports closed. After completion of vault suspension, fissurectomy was done in cases of fissure in ano. In cases in which rectocele still persisted posterior colpoperenioraphy was done. Intraoperative record maintained for total time of surgery, amount of blood loss, size of mesh and any complications (Table 3). Catheterization continued for 24 hours postoperatively. Single dose diclofenac $(50 \mathrm{mg} / \mathrm{ml})$ given 8 hours post operatively for pain relief. All patients were mobilized within 24 hours. Catheter removed and were observed for any voiding or defecatory problems (Table 4). All patients were discharged on $2^{\text {nd }}$ postoperative day with instruction to refrain from strenuous and sexual activity and use analgesics and antibiotics prescribed at discharge and come for follow up on $7^{\text {th }}$ post-operative day.

Further follow up were done after 2, 6, and 12 months post operatively, and then yearly upto 10 years. All patients were enquired about their relief of symptoms that existed prior to surgery, any new problems, satisfaction with surgery, improvement in quality of life and sexual activity (Table 5). All patients were examined for vault prolapse by per speculum examination using POP-Q scale. The primary measure for successful objective outcome was the absence of vaginal vault prolapse. The secondary outcomes included intra and postoperative complications, operating time, amount of blood loss, complications due to anesthesia and post-operative recovery. These patients were advised follow-up at interval of 2 month, 6 month and then yearly follow-up for 10 years.

The SPSS version 22.0 software program was used for statistical analysis. No ethical approval was needed for this study.

\section{RESULTS}

The mean age was 52 years and ranged from (30-75 years). Average weight was $55 \mathrm{~kg}(40-80 \mathrm{~kg})$, (Table 1).

All women were multiparous and had home deliveries and belonged to rural areas. $32 \%$ cases had under gone tubectomy operations. All patients presented with complaint of something coming out of private parts with associated chronic back ache in $56 \%$ cases, (Table 2 ).

Pre-operative blood transfusion for severe anaemia correction was done in $24 \%$ cases. No intra/ postoperative blood transfusion was required in any case. Vaginal hysterectomy was completed with average time of 35 minutes and laparoscopic sacrocolopopexy in 15 minutes, (Table 3).

Only $20 \%$ cases required endotrachial intubation. Vagina was markedly elongated in all cases of procedentia and so we required $2-4 \mathrm{~cm}$ length of mesh. 3-4 tackers were required in all cases. Associated anterior colporaphy was done in $10 \%$ cases. Posterior colporapphy was also done in $10 \%$ ofcases. In $8 \%$ cases fissurectomy was done for fissure in ano after completion of laparoscopic procedure. No intraoperative complications like bladder, ureteric or bowel injury or haemorrhage occured in our series. No postoperative complications due to anaesthesia or prolonged time of surgery like venous thromboembolism, neuropraxia was seen. Postoperative stay of all patients in hospital was uneventful (Table 4). 
Table 1: Patient profile, $n=25$.

\begin{tabular}{|c|c|c|}
\hline Variable & Number & Percentage \\
\hline \multicolumn{3}{|l|}{ Age in Years } \\
\hline $25-35$ & 03 & 12 \\
\hline $35-45$ & 05 & 20 \\
\hline $45-55$ & 06 & 24 \\
\hline $55-65$ & 07 & 28 \\
\hline $65-75$ & 04 & 16 \\
\hline \multicolumn{3}{|l|}{ Weight (Kgs) } \\
\hline $40-50$ & 08 & 32 \\
\hline $50-60$ & 08 & 32 \\
\hline $60-70$ & 06 & 24 \\
\hline $70-80$ & 03 & 12 \\
\hline \multicolumn{3}{|l|}{ Parity } \\
\hline 1 & Nil & Nil \\
\hline 2 & 04 & 16 \\
\hline 3 & 04 & 16 \\
\hline$>4$ & 17 & 68 \\
\hline \multicolumn{3}{|l|}{ Menopausal Status } \\
\hline Premenopausal & 09 & 36 \\
\hline Postmenopausal & 16 & 64 \\
\hline Associated surgical problems & 02 & 08 \\
\hline Gall bladder calculus & 01 & 04 \\
\hline Uretero vesical calculus & 04 & 08 \\
\hline Fisuure in Ano & - & - \\
\hline \multicolumn{3}{|l|}{ Associated medical problems } \\
\hline Hypertension & 13 & 52 \\
\hline Diabetes mellitus & 03 & 12 \\
\hline Bronchial asthma & 03 & 12 \\
\hline Severe anemia & 06 & 24 \\
\hline
\end{tabular}

Table 2: Complaints related to prolapse.

\begin{tabular}{|c|c|c|}
\hline Variable & Number & Percentage \\
\hline \multicolumn{3}{|l|}{ Presenting Complaints } \\
\hline $\begin{array}{l}\text { Something coming out of } \\
\text { private parts }\end{array}$ & 25 & 100 \\
\hline \multicolumn{3}{|l|}{ Associated problems } \\
\hline \multicolumn{3}{|l|}{ Urinary symptoms } \\
\hline Urinary retention & 05 & 20 \\
\hline Urinary incontinence & 01 & 04 \\
\hline $\begin{array}{l}\text { The need to reduce the prolapse } \\
\text { manually before voiding }\end{array}$ & 23 & 92 \\
\hline \multicolumn{3}{|l|}{ Bowel symptoms } \\
\hline Constipation & 10 & 40 \\
\hline Pain during defecation & 06 & 24 \\
\hline $\begin{array}{l}\text { The need to reduce prolapse } \\
\text { Manually before defecating }\end{array}$ & 23 & 92 \\
\hline Chronic abdominal pain & 08 & 32 \\
\hline Backache & 14 & 56 \\
\hline Bleeding per vaginum & 02 & 08 \\
\hline \multicolumn{3}{|c|}{ Coital difficulty in sexually active patients $(n=10)$} \\
\hline Dyspareunia & 03 & 30 \\
\hline Loss of vaginal sensation & 06 & 60 \\
\hline Vaginal flatus & 10 & 100 \\
\hline
\end{tabular}

Table 3: Intra operative details, $n=25$.

\begin{tabular}{|c|c|c|}
\hline Surgical time (Minutes) & Average & Range \\
\hline Vaginal hysterectomy & 35 & $25-45$ \\
\hline Laparoscopic sacrocolopexy & 18 & $15-25$ \\
\hline Anterior colporaphy & 12 & $10-15$ \\
\hline Posterior colpoperinoraphy & 12 & $10-15$ \\
\hline Total surgical time & 60 & $55-70$ \\
\hline Type of anesthesia & Number & $\%$ \\
\hline $\begin{array}{l}\text { Spinal anesthesia while doing } \\
\text { laparoscopy supplemented }\end{array}$ & 25 & 100 \\
\hline $\begin{array}{l}\text { With sedative short acting muscle } \\
\text { relaxant and IPPR }\end{array}$ & 21 & 84 \\
\hline Endotracheal intubation & 04 & 16 \\
\hline $\begin{array}{l}\text { Length of polypropylene mesh (in } \\
\text { cms) }\end{array}$ & Number & $\%$ \\
\hline 02 & 03 & 12 \\
\hline $2-4$ & 22 & 80 \\
\hline Number of tackers & Number & $\%$ \\
\hline 03 & 03 & 12 \\
\hline 04 & 20 & 80 \\
\hline 05 & 02 & 08 \\
\hline Mean blood loss (ml) & Number & $\%$ \\
\hline $20-30$ & 21 & 84 \\
\hline $30-40$ & 04 & 16 \\
\hline$>40$ & Nil & Nil \\
\hline Complications during surgery & Number & $\%$ \\
\hline Hemorrhage & Nil & Nil \\
\hline Bladder Injury & Nil & Nil \\
\hline Ureteric injury & Nil & Nil \\
\hline Bowel injury & Nil & Nil \\
\hline Conversion to Laprotom & Nil & Nil \\
\hline
\end{tabular}

Table 4: Post-operative details, $n=25$.

\begin{tabular}{|lllll|}
\hline Parameter & $\begin{array}{l}\text { During } \\
\text { hospital } \\
\text { stay of } 2 \\
\text { days }\end{array}$ & $\begin{array}{l}\text { 7th Post- } \\
\text { operative } \\
\text { day } \\
\text { (O.P.D) } \\
\text { follow up }\end{array}$ \\
\hline $\begin{array}{l}\text { Voiding difficulty after } \\
\text { catheter removal }\end{array}$ & N & \% & N & \% \\
\hline Difficulty in defecation & 02 & Nil & Nil & Nil \\
\hline Post-operative ilieus & Nil & Nil & Nil & Nil \\
\hline Pain in abdomen & & & & \\
\hline Mild & 14 & 56 & Nil & Nil \\
\hline Moderate & 10 & 16 & Nil & Nil \\
\hline Severe & Nil & Nil & Nil & Nil \\
\hline Vagina bleeding & Nil & Nil & Nil & Nil \\
\hline Vaginal discharge & Nil & Nil & Nil & Nil \\
\hline Mild nausea and vomiting & 05 & 20 & Nil & Nil \\
\hline Venous thromboembolism & Nil & Nil & Nil & Nil \\
\hline Neuropraxian & Nil & Nil & Nil & Nil \\
\hline Respiratory problems & Nil & Nil & Nil & Nil \\
\hline Re-explorations & Nil & Nil & Nil & Nil \\
\hline
\end{tabular}


Total $80 \%$ of cases have completed 5 years follow-up on $1^{\text {st }}$ January 2016 and remaining $20 \%$ patients completed on $1^{\text {st }}$ January 2020 , with $100 \%$ subjective and objective improvement. 8 patients $(32 \%)$ cases have completed 10 years follow up with no complaints (Table 5).

\section{DISCUSSION}

From January 2001 to December 2008, we had operated on 50 cases of procedentia and used different techniques to prevent vault prolapse namely culdoplasty and different vault suspension techniques but vault prolapse occurred in 40 cases i.e., $80 \%$ cases on long term followup. In these cases we did LSC with standard technique. Our experience made us realize that in cases of procedentia the strength of ligaments is weak and so we started using mesh in cases of procedentia for suspension of vault and had been practicing this technique for last 12 years. The mean operating time for LSC was 18 minutes (range 15-25 minutes) which is less than 64 minutes (range 50-95 minutes) by Price et al. ${ }^{1}$ This is because introduction and fixation of mesh vaginally saves time. The intra operative and post-operative complications like bladder, ureteric or bowel injury or hemorrhage were nil in our series. Hemorrhage from pre sacral venous plexus or median sacral vessels can be life threatening. Attachment of mesh to sacral promontory rather than sacral hollow can reduce the risk of bleeding. Conversion to laprotomy was not required in any case where as Nosti at el reported $2.4 \%$ conversion rate. ${ }^{7}$ In fact it has been our routine practice to visualize the vaginal vault, stumps and abdominal cavity to detect any unreported pathology or intraoperative hemorrhage from last 15 years and this reduces our conversion rates to laparotomy. ${ }^{8} \mathrm{We}$ have used $5 \mathrm{~mm}$ ports only with minimum tissue handling and this reduces post-operative pain, port site infections and port site hernia formation. Our all patient required only single dose diclofenac for postoperative pain relief. $40 \%$ of cases had chronic constipation prior to surgery and this persisted in only $24 \%$ of cases 6 months postoperatively. Patients were advised fiber rich diet and laxatives as and when required these defecatory problems were not because of sacro colpopexy but due to preoperative fissure in ano. Baessler et al found persistence of constipation in $38 \%$ of cases after sacralcolpopexy. ${ }^{9}$

Table 5: follow up details, $n=25$.

\begin{tabular}{|c|c|c|c|c|c|c|c|c|c|c|}
\hline \multicolumn{4}{|c|}{ Readmission due to bronchial asthma } & & \multirow{2}{*}{\multicolumn{2}{|c|}{$\begin{array}{c}04 \% \\
2 \text { year }(n=25)\end{array}$}} & \multirow{2}{*}{\multicolumn{2}{|c|}{5 year $(n=20)$}} & \multirow{2}{*}{\multicolumn{2}{|c|}{10 years $(n=8)$}} \\
\hline Problems & \multicolumn{2}{|c|}{2 months $(n=25)$} & 6 months (n=25) & & & & & & & \\
\hline $\begin{array}{l}\text { Subjective } \\
\text { findings }\end{array}$ & No. & Percentage & No. & Percentage & No. & Percentage & No. & Percentage & No. & Percentage \\
\hline $\begin{array}{l}\text { Vaginal } \\
\text { discharge }\end{array}$ & Nil & Nil & Nil & Nil & Nil & Nil & Nil & Nil & Nil & Nil \\
\hline $\begin{array}{l}\text { Vaginal } \\
\text { bleeding }\end{array}$ & Nil & Nil & Nil & Nil & Nil & Nil & Nil & Nil & Nil & Nil \\
\hline Backache & 02 & 08 & 02 & 08 & 02 & 08 & Nil & Nil & Nil & Nil \\
\hline $\begin{array}{l}\text { Pain during } \\
\text { defecation }\end{array}$ & 06 & 24 & 02 & 08 & 02 & 08 & Nil & Nil & Nil & Nil \\
\hline Pelvic pain & 04 & 16 & 01 & 04 & 01 & 04 & Nil & Nil & Nil & Nil \\
\hline $\begin{array}{l}\text { Urinary } \\
\text { problem }\end{array}$ & Nil & Nil & Nil & Nil & Nil & Nil & Nil & Nil & Nil & Nil \\
\hline \multicolumn{11}{|c|}{ Objective Assessment } \\
\hline \multicolumn{11}{|c|}{ Vault prolapse (POPQ system) } \\
\hline Stage 0 & Nil & Nil & Nil & Nil & Nil & Nil & Nil & Nil & Nil & Nil \\
\hline Stage 1 & Nil & Nil & Nil & Nil & Nil & Nil & Nil & Nil & Nil & Nil \\
\hline Stage 2 & Nil & Nil & Nil & Nil & Nil & Nil & Nil & Nil & Nil & Nil \\
\hline Stage 3 & Nil & Nil & Nil & Nil & Nil & Nil & Nil & Nil & Nil & Nil \\
\hline Stage 4 & Nil & Nil & Nil & Nil & Nil & Nil & Nil & Nil & Nil & Nil \\
\hline Mesh erosion & Nil & Nil & Nil & Nil & 01 & 04 & 01 & 04 & Nil & Nil \\
\hline $\begin{array}{l}\text { Vault } \\
\text { granulation }\end{array}$ & Nil & Nil & Nil & Nil & Nil & Nil & Nil & Nil & Nil & Nil \\
\hline $\begin{array}{l}\text { Urinary } \\
\text { incontinence }\end{array}$ & Nil & Nil & Nil & Nil & Nil & Nil & Nil & Nil & Nil & Nil \\
\hline $\begin{array}{l}\text { Fistula } \\
\text { formation }\end{array}$ & Nil & Nil & Nil & Nil & Nil & Nil & Nil & Nil & Nil & Nil \\
\hline
\end{tabular}

Chronic back ache was the most common associated problem in $56 \%$ cases of procedentia which persisted in only $8 \%$ of cases on follow-up. This back ache was again because of osteoporosis and nutritional problems and not related to procedure. All patients were given calcium and vitamin D supplementation postoperatively. Most 
women in our study who were sexually active had no coital problems post operatively also. Nosti at el also reported overall improvement in sexual activity after laparoscopic sacrocolpopexy. ${ }^{7}$ In young patients we also gave the options of uterine preservation and sacrospinous hysteropexy, as suggested by Detollenaere et al but all our patients had completed child bearing hence opted for hysterectomy. ${ }^{10} \mathrm{We}$ introduced the mesh vaginally, this not only reduced our operating time but fixation of mesh vaginally is also very easy for gynecologists as compared to laparoscopic suturing of mesh to vault. Carey et al used mesh vaginally to treat prolapse and reported anatomic success rate of $94 \% .{ }^{11}$ Fixation of mesh in circular fashion to uterosacral ligament, cardinal ligament, and to pubovesicocervical fascia anteriorly, rectovaginal fascia posteriorly leads to circular approximation of all important supports and this also helps in prevention of enterocele. The use of synthetic material to suspend the vagina has the potential complications of mesh erosion. In our series mesh erosion occurred only in one case i.e. (4\%), 2 years after surgery which was asymptomatic hence no active management was done. Bergersen et al also advocated that conservative management may be attempted for asymptomatic mesh exposure. ${ }^{12}$ The overall incidence of mesh erosion has been up to $9 \%$ with Marlex gore tex and Merselene, up to $11 \%$ with Teflon. Shah et al found that incidence of mesh erosion (including exposure, extrusion and perforation varies from $0-33 \% .^{13}$ They also noted that multifilament polypropylene, non knitted implants were more frequently associated with infection than monofilament polypropylene implants (70\% vs 39\%). Our mesh infection rates were nil. Preoperative use of antibiotics, through antisepsis, gentle tissue handling and meticulous hemostasis were our strategies to prevent mesh infection.

Various observational studies have shown good anatomical cure rates (more than 90\%) in 1-2 years follow-up. ${ }^{14}$ We have not yet found any case of vault prolapse till date and we target to have yearly follow-up up to 10 years for all patients. Bojahr et al reported a total persistence or recurrence rate of $10.4 \%$, Wong et al, had an average follow up of 3 years and have demonstrated high prevalence of recurrent anterior and posterior compartment defects through ultrasonography in cases of LSC. ${ }^{15,16}$

This study has several limitations. This study included 25 patients. But Bijalwan et al reported the life time risk for women to undergo surgery for the management POP is about $11 \%$ and $30 \%$ of these women will need additional surgery because of prolapse recurrence. ${ }^{17}$ In our study we included only cases of procendentia and designed the surgery to prevent recurrence. It was noted that majority of the respondents $(87 \%)$ visited public health care facilities for POP. We are in private setup, so to have these types of cases, operated and complete follow up justifies our limited number of patients.

\section{CONCLUSION}

Vault prolapse poses a challenge to the gynecologist surgeon especially in cases of procedentia. Restoration of vagina to its normal anatomic position remains the most important fact to prevent vault prolapse. Our technique took into consideration various techniques described for prevention of vault prolapse till date and we found our. combined vaginal and laparoscopic approach very easy, less time taking with negligible complication rates.

Funding: No funding sources

Conflict of interest: None declared

Ethical approval: The study was approved by the Institutional Ethics Committee

\section{REFERENCES}

1. Price N, Slack A, Jackson S.R, Laparoscopic sacrocolpopexy: An observational study of functional and anatomic outcomes. Int urogynecol J. 2011;22(1):77-82.

2. DeLanncey JOL, Anatomic aspects of vaginal eversion after hysterectomy. Am J Obstet Gynecol. 1992;166:1717-24.

3. Persu C, Chapple CR, Cauni V, Gutue S, Geavlete P, Pelvic Organ Prolapse Quantification System (POP-Q) - a new era in pelvic prolapse staging. J Med Life. 2011;4(1):75-81.

4. RCOG/BSUG. Post hysterectomy vaginal vault prolapse, Green-top Guidelines. 2015146:1-21.

5. RCOG/BSUG. The management of post hysterectomy vaginal vault prolapse, Green-top Guidelines. 2007;46:1-13.

6. Nygaard IE, McCreery R, Brubaker L, Connolly AM, Cundiff G, Weber AM, et al, Abdominal Sacrocolpopexy: A Comprehensive review. Am J Obstet Gynecol. 2004;104(4):805-22.

7. Nosti PA, Andy UU, Kane S, White DE, Harvi HS, Lowenstein L, et al, Outcomes of abdominal and minimally invasive sacrocolpopexy: A retrospective cohort study, Female pelvic medicine and reconstructive surgery. 2014;20(1):33-7.

8. Agrawal P, Agrawal R, Chandrakar J. Role of laparoscopy in vaginal hysterectomy for non prolapsed uterus. J Obstet Gynecol. 2007;57(2):151-4.

9. Baessler, Kaven MD, Schuessler, Bernhard MD. Abdominal sacrocolpopexy and anatomy and function of the posterior compartment. Obstet Gynecol. 2001;97(5):678-84.

10. Detollenaere RJ, Boon J, Stekelenburg J, Inthou t J, Vierhout ME, Kluivers KB, et al. Sacrospinous hysteropexy versus vaginal hysterectom y with suspension of the uterosacral ligaments in women with uterine prolapse stage 2 or higher: multicentre randomised non-inferiority trial. BMJ. 2015;351:3717.

11. Carey M, Slack M, Higgs P, Williams MW, Cornish A. Vaginal surgery for pelvic organ 
prolapse using mesh and a vaginal support device. BJOG. 2008;115(3):391-7.

12. Bergersen A, Hinkel C, Funk J, Twiss CO. Management of vaginal mesh exposure: A systematic review. Arab Jurol. 2019;17(1):40-8.

13. Shah HN, Badlani GH. Mesh complications in female pelvic floor reconstructive surgery and their management: A systematic review. Indian J Urol. 2012;28(20):129-53.

14. Lee RK, Mottrie A, Payne CK, Waltregny D. A review of the Current Status of laparoscopic and Robot-assisted Sacrocolpopexy for Pelvic Organ Prolapse. Euro Urol. 2014;65:1128-37.

15. Bojahr B, Tchartchian G, Waldschmidt $M$, Schollmeyer T, Wilde RLD. Laparoscopic sacropexy: a retrospective analysis of perioperative complications and anatomical outcomes. JSLS. 2012;16(3):428-36.

16. Wong V, Rojas RG, Shek KL, Chou D, Moore KH, Dietz HP, Laparoscopic sacrocolpopexy: how low does the mesh go? ISUOG. 2017;49(3):404-8.

17. Bijalwan RP, Bhagavatula M, Semwal VD, Rawat $\mathrm{P}$, Anand V. Morbidity of Uterine Prolapsed among the Women in the Chakrata Block of Dehradun District. Ind J Community Heal. 2015;27(1):103-9.

Cite this article as: Agrawal P, Agrawal R, Chandrakar J. Prevention of vault prolapse in cases of procedentia using combined vaginal and laparoscopic approach for vault suspension: Agrawal's technique. Int J Reprod Contracept Obstet Gynecol 2021;10:296-302. 